\title{
A Study of User Acceptance Using Google Software as a Service (Saas)
}

\author{
Naicheng Chang ${ }^{1}$, Chengche Chiang ${ }^{2}$ and Alan Hopkinson ${ }^{3}$ \\ ${ }^{1}$ General Education Center Tatung University, Taipei, Taiwan \\ ${ }^{2}$ Institute of Astronomy and Astrophysics Academia Sinica, Taipei, Taiwan \\ ${ }^{3}$ Shepherd Library Middlesex University, United Kingdom \\ ncchang@ttu.edu.tw, ccchiang@asiaa.sinica.edu.tw, a.hopkinson@mdx.ac.uk
}

\begin{abstract}
This study uses Unified Theory of Acceptance and Use of Technology (UTAUT) as the framework for the research design model and the SaaS provided by Google as a sampling subject to explore the relationship between acceptance and the actual use of the service in Taiwan. Research findings include: 1) the findings support the importance of performance, effort and social influence on intention towards Google SaaS, in which performance has the highest impact and the effort has a comparatively unnoticeable impact on intention; 2) the performance is a significant determinant on intention for users less than 30 years old and experience with less than one year, but this impact reduced with increasing age and experience; 3) the intention has considerable positive connection on its actual use; 4) users believe that $\mathrm{SaaS}$ is the future trend.
\end{abstract}

Index Terms - User Acceptance; usage; Software as a Service (SaaS); Unified Theory of Acceptance and Use of Technology (UTAUT)

\section{Introduction}

With the advance of the information technology network infrastructure environment, large amounts of data have moved to the Internet as resources on demand which form the concept of Cloud Computing, the natural evolution of the widespread adoption of virtualization, service-oriented architecture and utility computing [1].

Applying cloud computing in the service industry has been forming an important future trend worldwide, and so understanding the behavioral adoption requirement is crucial to researchers and industry players. The Software as a Service (SaaS) platform with broad network access from cloud computing provides shared resources very different from the previous with their relatively individual maintenance [2]. Current studies on cloud computing in Taiwan are mostly on sectors of software and hardware technology, business applications and information security, with very less focus on user studies [3]. Google cloud service has been becoming prevalent recent years in Taiwan for the Android technology in the smartphone platform. It starts to engulf the services, particularly the free email service, from the most popular local web portal Yahoo!Kimo [4], which renamed from Yahoo!Taiwan after it merged two local web portals Kimo and Wretch. The purposes of this research are to 1) explores the applicability of applying Unified Theory of Acceptance and Use of Technology (UTAUT) to explain the user's Behavioral Intention (BI) to SaaS provided by Google; 2) analyses the level of the use of SaaS and the reasons which affect the user Behavioral Intention to the service; 3) explores the relationship between the level of the user Behavioral Intention (BI) of SaaS and the Use Behavioral (UB) of the service.

The UTAUT derives from the Technical Acceptance Model (TAM), which is heavily used to evaluate the potential for success of new technology initiation, and helps identify factors likely to influence adoption of technology (Davis et al., 1989). In the TAM, the perceived usefulness and perceived ease of use are two basic determinants for attitudes to use a specific technology initiation. Its purpose is to explain users behavioral intention and the use behavioral from the point of the users' perception.

Researches from Venkatesh et al. (2003) claimed that the explanation power of user's behavioral intention and the use behavioral of UTAUT could reach up to $70 \%$, and they also claimed that it was a more effective model than other ever before. They testified over eight theories and 32 constructs with empirical researches, and eventually integrated into four constructs as external variables: Performance Expectancy (PE), Effort Expectancy (EE), Social Influence (SI) and Facilitating Conditions (FC). The three constructs PE, EE and SI, are the significant factors which influence directly users' behavioral intention; whereas, FC and $\mathrm{BI}$ affect directly to the users' actual use behavioral. In the UTAUT model, four control variables are Gender, Age, Experience and Voluntariness of Use. In research practices, the corresponding external and control variables in the model often change with a different research scenario.

Few researches were conducted to investigate the factors affecting cloud computing services applying UTAUT constructs in Taiwan. Cian (2010) studied the key factors for consumers to use cloud computing services with several riskrelated constructs such as Performance Risk and Privacy Risk except the already existed UTAUT constructs. Yen (2011) investigated how network externalities affect UTAUT and its influence on user acceptance of SaaS. The Structural Equation Modeling (SEM) was applied to testify over the theoretical model. Liu (2012) explored the user attitudes of payment willingness on Office 365 cloud application service with additional Perceive Service Quality, Perceive Sacrifice and more as additional constructs in the UTAUT. Huang (2012) examined behavioral intention of tour customers on Google Earth 3D online tour systems. 


\section{Research Model and Research Methodology}

This study modified four constructs in UTAUT from into three constructs: PE, EE and SI, and extended the original four control variables into five: Gender, Age, Experience, Occupation and Education. Google SaaS has been put in public online for years, and it is reasonable to ignore to the $\mathrm{FC}$ construct. Furthermore, the Google SaaS is there for free of use, it also is reasonable to ignore the control variable of Voluntariness of Use. We added control variables of Occupation and Education for the reason that the two variables could be crucial factors to testify over the level of the behavioral intention for users to use the service. The research model of UTAUT after modification is showed in Fig.1 as below.

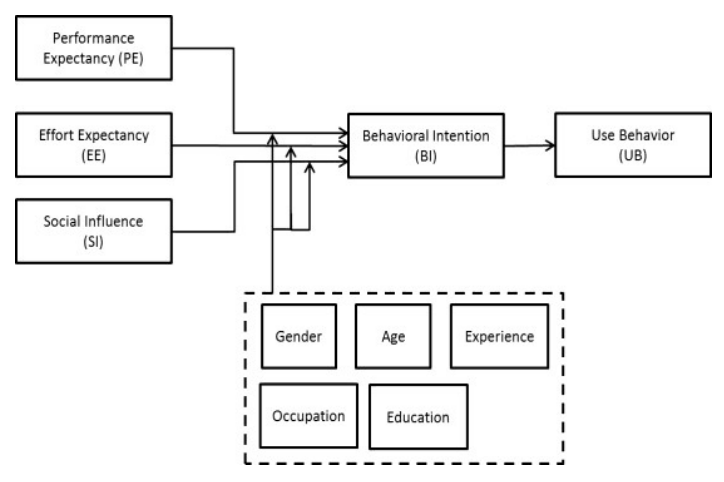

Fig. 1 Research model

The research questionnaire with total of 24 questions was designed accordingly representing each variable of the framework into four parts: user expectations, use behavioral, profile of the respondents and behavioral intention. User expectations include seven questions related to $\mathrm{PE}$, five questions related to EE and three questions are for SI. Total four questions are for actual usage of Google SaaS. Respondents' profile covers four questions. Behavioral intention has one question. In the questionnaire, we listed a number of SaaS services provided by Google for respondents' references such as Gmail, Picasa, Youtube, Google Docs, Paid Cloud storage and so on. The value ranges of control variables are presented in Table 1.

TABLE I Value Ranges of the Control Variables

\begin{tabular}{ll}
\hline Variable & Values \\
\hline Age & $-20,21-30,31-40,41-50,51-60,61+$ \\
Gender & Female, Male \\
Education & High school, Bachelors, Master/PhD \\
Occupation & $\begin{array}{l}\text { Military/Government/Teacher, Service, IT, Self-employed, } \\
\text { Student, Other }\end{array}$ \\
Experience & Occasionally, -1, 1-3,3+ (year) \\
\hline
\end{tabular}

We used 5-point Likert Scale to measure the parts of user expectations and behavioral intention of the questionnaire, and used multiple choices for the part of actual use of Google SaaS. The questionnaire was pre-tested with 20 volunteers and was modified accordingly before it was put online. The questionnaire was measured with anonymous. The administration time was from 14 May to 27 May 2011. 201 valid questionnaires were collected.

We used SPSS 19.0 for data analysis. This includes independent samples t-test and one-way Analysis of Variance (ANOVA) to analysis the level of influence of the variables to the behavioral intention. This also includes Path Analysis in Linear Regression to analysis the level of influence of the three constructs to the behavioral intention and use behavioral. It also analysis the level of influence of the control variables to the three constructs. The result shows that the overall Cronbach $\alpha$ is 0.883 , which indicates that the research credibility is fairly good.

\section{Findings}

\section{A. Descriptive Statistics}

The research results are discussed as below in four aspects: profile of the respondents, users experience, actual use of Google SaaS and users' behavioural intention.

1) Profile of the respondents: $62.7 \%$ of respondents are female. The ages of 21 to 30 -year-old and 31 to 40 -year-old are the top two age groups which account for $34.3 \%$ and $32.8 \%$ respectively. Occupations of militants/government servants/teachers are the top one group which accounts for $33.3 \%$, and the group of students is the next which accounts for $25.9 \%$. The respondents who have master $/ \mathrm{PhD}$ degree are the biggest group which accounts for $52.2 \%$.

2) Users' experience: $75.6 \%$ of respondents go online for more than three hours every day and only $3.5 \%$ of respondents go online for less than one hour. $49.8 \%$ of respondents use Google SaaS every day and only $3 \%$ of respondents who occasionally use the services. $61.7 \%$ of respondents have three years use experience of Google SaaS and only $1.5 \%$ of respondents have very limited experience.

3) Actual use of Google SaaS: The most popular use (by number of respondents) of SaaS provided by Google are Gmail (169), Youtube (144), Google Map (138), Picasa (107), Google Docs (83), Google Calendar(72). All respondents use at least one of the six services. $75 \%$ of respondents use at least more than three of the six services.

4) Users' behavioral intention: 152 respondents which account for $75.6 \%$ agree that they are delighted to use Google $\mathrm{SaaS}$, and 12 respondents strongly agree in this aspect. It shows that more than $80 \%$ of respondents have incorporated Google SaaS as tools into their methods of managing daily things.

\section{B. Correlations}

Pearson correlation test is applied to the external variables

$\mathrm{PE}, \mathrm{EE}, \mathrm{SI}$ to measure their influence to BI for Google SaaS. The results are displayed in TABLE 2. The results show that the three external variables have positive correlation to BI in which PE has the most significant correlation on adoption Google SaaS $(\mathrm{R}=0.591 ; \mathrm{P}=0.000)$ and $\mathrm{EE}$ has the lowest correlation $(\mathrm{R}=0.354 ; \mathrm{P}=0.000)$. The results also show positive correlation in peer group, in which $\mathrm{PE}$ and $\mathrm{EE}$ has the most 
significant correlation $(\mathrm{R}=0.484 ; \mathrm{P}=0.000)$; whereas, $\mathrm{EE}$ and $\mathrm{SI}$ has the lowest correlation $(\mathrm{R}=0.254 ; \mathrm{P}=0.000)$.

TABLE 2 Correlations Analysis

\begin{tabular}{lcccc}
\hline & \multicolumn{1}{l}{ PE } & EE & \multicolumn{1}{l}{ SI } & BI \\
\hline PE & 1 & $0.484^{* *}$ & $0.464^{* *}$ & $0.591^{* *}$ \\
& & 0.000 & 0.000 & 0.000 \\
EE & $0.484^{* *}$ & 1 & $0.254^{* *}$ & $0.354^{* *}$ \\
& 0.000 & & 0.000 & 0.000 \\
SI & $0.464^{* *}$ & $0.254^{* *}$ & 1 & $0.472^{* *}$ \\
& 0.000 & 0.000 & & 0.000 \\
BI & $0.591^{* *}$ & $0.354^{* *}$ & $0.472^{* *}$ & 1 \\
& 0.000 & 0.000 & 0.000 & \\
\hline
\end{tabular}

\section{Regression Analysis}

The findings support the UTAUT theory that performance, effort and social influence have positive impact on intention towards Google SaaS, in which performance and social influence have far more impact than effort on intention. This could be that the services is getting more accessible with times and is more common among people when users think high performance expectancy and social influence are important determinants towards the service. The outcome also demonstrates that the intention has considerable positive connection on its actual use. The results with $\beta$ values are described below.

1) Users' behavioral intention has significant effect on users' actual use $(\beta=0.373)$.

2) Performance expectancy towards Google SaaS has very noticeable effect on users' willingness to use the services $(\beta=0.436)$.

3) Effort expectancy towards Google SaaS supports unnoticeably but positive on users' willingness to use the services $(\beta=0.080)$.

4) Social influence towards Google SaaS shows positive impact on users' willingness to use the services $(\beta=0.250)$.

\section{Analysis of Control Variables}

Venkatesh et al. (2003) believes that user intention would be influenced by the interfering factors such as gender, age and so on. This analysis was undertaken applying t-test, ANOVA and Regression Analysis to investigate the five interfering factors in the research model that affect the behavioral intention to use the service. The findings are analysis as follows.

1) Gender: Female take more account than male on if Google SaaS is easy to use. The results shows male affects positively more than female as suggested by Venkatesh et al. (2003) which indicate that male considers more if Google SaaS could provide higher performance. Intention has positive affect on actual use of the services for both genders, and it affects more on female than male. Social influence has strong support on female's intention but little on male.

2) Age: There is a very positive and noticeable impact with performance on intention for age group less than 50, and the impact is increased with decreasing age. There is a positive and significant impact with social influence for age group larger than 30, and the impact is increased with increasing age. The impact of use intention on actual use for age group less than 30 and more than 50 is obvious. And the latter age group is affected more on actual use than the former age group.

3) Experience: Users with more than three years experience of Google SaaS, their user intention are affected positively by performance and social influence. The performance demonstrates even stronger impact on intention to users with experience less than one year, and the actual use of this experience group is affected positively by intention.

4) Occupation: The performance has high positive impact on users' intention to three kinds of user occupation. The size of the extent of its influence from the highest is IT, student and Military/Government/Teacher. It is interesting to see that users in IT sector their intention has minimum support on use behavioral. For users whose occupation is Military/Government/Teacher, their intention is strongly influenced by effort expectancy. For users in service sector, their intention is strongly influenced by social influence.

5) Education: For high school and Master/PhD users, their intention is influenced dramatically with positive impact by performance. And the high school users receive more impact than Master $/ \mathrm{PhD}$. It is interesting to observe that high school users' intention is influenced significantly with negative impact by effort expectancy. It shows that for high school users, the more ease to use or high effort expectancy, the lower willingness to use the service. For bachelors and Master/PhD users, their intention is influenced significantly by social influence. And the bachelors receive more impact than Master/PhD. It is worth to notice that users of all types of education level their actual use is influenced obviously by intention. The size of the extent of its influence from the highest is high school, bachelors, and Master/PhD.

Overall, there is no significant difference for any type of education level to intention, performance, effort and social influence. Users with longer experience, their intention are affected positively by performance and social influence; whereas, their intention has minor impact on their actual use.

\section{Conclusion}

SaaS has become a common delivery model for many business applications, in which, Google features several web applications with similar functionality to traditional office suits. When the recent fashion of Android technology in portable devices such as tablet computer and smartphone, people in Taiwan are transferring from Yahoo!Kimo to Google SaaS. This might explain that the high respondents in this study are from government and research sectors with age range between 21-40 years and with Master/PhD education level. They go online more than three hours every day and use at least three types of Google SaaS services with experience more than three years. This also could be factor that performance and social influence play a far more significant role than effort as direct determinants of user acceptance and usage behaviroal towards Google SaaS. 
This study concludes that users are looking forward to convenience and usefulness from Google SaaS, and at the same time they believe that the service is the future trend. The external influences will enhance the behavioral intention. Users pay trivial attention to effort expectancy towards Goolge SaaS. Lastly, the results reveal interesting connections of users' behavioral intention and use behavioral with influence factors gender, age, experience, occupation and education.

\section{Acknowledgment}

The Financial support for this research from Tatung University, Taiwan, under the grant B100-W02-069 is gratefully acknowledged.

\section{References}

[1] National Institute of Standards and Technology (NIST), "The NIST Definition of Cloud Computing," 2009. http://csrc.nist.gov/groups/SNS/cloud-computing/cloud-def-v15.doc

[2] S. O'Neill,Simpson, " Forrester: Public Cloud Growth to Surge, Especially SaaS," CIO, 2011. http://www.cio.com/article/680673/Forrester_Public_Cloud_Growth_to_ Surge_Especially_SaaS
[3] C. Chiang, "A user study of Software as a Service (Saas)-the case of Google," unpublished dissertation of Graduate Institute of Library and Information Studies, National Taiwan Normal University, 2011.

[4] Yahoo!Kimo, 2013. http://tw.yahoo.com

[5] F. D., Davis, R. P. Bagozzi, and P. R. Warshaw, "User acceptance of computer technology: a comparison of two theoretical models," Management Science, vol.35, no.8, pp. 982-1003, 1989.

[6] V.,Venkatesh, M.G., Morris, G.B., Davis, and F.D., Davis, "User acceptance of information technology: Toward a unified view," MIS Quarterly, vol.27, no.3, pp. 425-478, 2003.

[7] Y. Cian, "A study of cloud computing services based on the consumer adoption behaviors," unpublished dissertation of Graduate School of Business Administration, Chung Yuan Christian University, 2010.

[8] Y. Yen, "Applying UTAUT model to explore the antecedents of behavioral intentions for using cloud computing services: a case of Software as a Service," unpublished dissertation of Graduate School of Business Administration, Soochow University, 2011.

[9] C. Liu, "The payment willingness of end user for cloud application service," unpublished dissertation of Graduate Institute of Information and Logistics Management, National Taipei University of Technology, 2012.

[10] Z. Huang, "The influence of $3 D$ online tour systems for behavior intention of tour customers: a case study on Google Earth," unpublished dissertation of Graduate School of Information Management, Da-Yeh University, 2012. 